\title{
Article
}

\section{A Scientist-Practitioner Approach to an On-Field Assessment of Mental Skills in Collegiate Soccer Student-Athletes}

Amber, Shipherd, Itay, Basevitch, Filho, Edson and Lael, Gershgoren

Available at http://clok.uclan.ac.uk/22102/

Amber, Shipherd, Itay, Basevitch, Filho, Edson ORCID: 0000-0002-8548-4651 and Lael, Gershgoren (2018) A Scientist-Practitioner Approach to an On-Field Assessment of Mental Skills in Collegiate Soccer Student-Athletes. Journal of Sport Psychology in Action, 9 (3). ISSN 2152-0704

It is advisable to refer to the publisher's version if you intend to cite from the work. http://dx.doi.org/10.1080/21520704.2018.1463330

For more information about UCLan's research in this area go to http://www.uclan.ac.uk/researchgroups/ and search for <name of research Group>.

For information about Research generally at UCLan please go to http://www.uclan.ac.uk/research/

All outputs in CLoK are protected by Intellectual Property Rights law, including Copyright law. Copyright, IPR and Moral Rights for the works on this site are retained by the individual authors and/or other copyright owners. Terms and conditions for use of this material are defined in the policies page.

\section{CLoK}

Central Lancashire online Knowledge www.clok.uclan.ac.uk

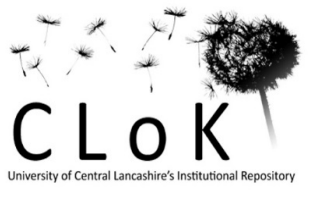


1

2

3

4 athletes themselves. Therefore, an alternative, more reliable and ecologically valid method of

5 assessing mental skills is needed for sport psychology practitioners. As such, the purpose of this

6 paper is to illustrate how an authentic field-based mental skills program assessment was used in

7 the off-season for collegiate soccer teams. Following discussions between the sport psychology

8 practitioners and coaching staff, pre- and post- test activities were developed and implemented

9 on an outdoor soccer field, which was determined to be a more authentic "real-world"

10 environment. Activities evaluated situational and tactical awareness, on-field communication,

11 shooting self-efficacy, and performance under pressure and fatigue. The field assessment

12 experience provided a good method for the sport psychology practitioners to observe

13 improvements in mental skills, and the student-athletes and coaches reported that the activities

14 and debrief demonstrated the involvement of mental skills in every aspect of their soccer

15 performance.

16 Keywords: Sport psychology, program evaluation, student-athletes 
A Scientist-Practitioner Approach to an On-Field Assessment of Mental Skills in Collegiate

\section{Soccer Student-Athletes}

At high levels of competition, such as collegiate athletics, oftentimes the deciding factor that determines athletic success on a given day is which athlete or team has the mental edge over the other (Weinberg \& Gould, 2015). A wide array of psychosocial variables (e.g., anxiety, communication, concentration, confidence, decision-making) have been found to have an impact on athletic performance, especially in collegiate level and adult athletes (Gee, 2010; Weinberg \& Gould, 2015). Sport psychology practitioners work to arm athletes and coaches with skills and tools to optimize performance and minimize the negative impact of such psychosocial variables on performance. The field of sport psychology has continued to increase over the past 20 years with more and more sport psychology or mental skills training programs being developed for collegiate and elite level athletes and teams (Blann, Shelley, \& Gates, 2011; Weinberg \& Gould, 2015). It has been recommended that effective mental skills training programs at the collegiate level be implemented in the off-season and address performance issues such as arousal regulation, mental preparation, confidence, and attention or concentration skills (Weinberg \& Gould, 2015).

While significant growth has been made in the usage of sport psychology services, a challenge still faced by many practitioners in the field is the "buy-in" of services and demonstrating their value (Blann et al., 2011). Oftentimes this challenge stems from the lack of education coaches and athletes have regarding the nature of sport psychology services and the impact of sport psychology services on performance (Gee, 2010; Zakrajsek, Martin, \& Zizzi, 2011). One factor contributing to coaches and athletes misconceptions regarding sport psychology services is that the evaluation of sport psychology programs or mental skills training 
41 programs is too often overlooked. However, coaches who are utilizing sport psychology services

42 want to know if the services are benefitting their athletes (Weinberg \& Gould, 2015). Oftentimes

43 coaches want to see performance indicators used as the primary index of sport psychology

44 service effectiveness. However, it is difficult to attribute changes in performance to the sport

45 psychology services alone (Woodcock, Duda, Cumming, Sharp, \& Holland, 2012).

When sport psychology services are evaluated, questionnaires aimed to assess mental

47 skills are frequently used as an indicator of service effectiveness (Beckmann \& Kellmann, 2003).

48 However, coaches and the athletes themselves, may not place as much value on questionnaires as

49 sport psychology practitioners. Beckmann and Kellman (2003) highlight the need to have both

50 coach and athlete commitment, understanding, and "buy-in" when implementing questionnaires

51 or more formal psychological assessments. Athletes may not respond truthfully on questionnaires

52 due to social desirability or the fear that their coaches may have access to the results (Woodcock

53 et al., 2012). Additionally, Weinberg and Gould (2015) recommend using both quantitative and

54 qualitative data to evaluate program effectiveness. Therefore, an alternative, more reliable and

55 ecologically valid method of assessing mental skills is needed for sport psychology practitioners.

56 Utilizing a more authentic assessment will aid in demonstrating the usefulness and impact of

57 mental skills to both coaches and athletes. Accordingly, the purpose of this paper is to illustrate

58 how an authentic field-based mental skills program assessment was used in the off-season for

59 collegiate soccer teams.

60

\section{Background}

The four authors had been working as Mental Performance Consultants (MPCs) with

62 men's and women's collegiate National Association of Intercollegiate Athletics (NAIA) soccer

63 teams for approximately three and a half years. Neither team had received any previous mental 
skills training. Both teams were coached by the same head coach, who had five years coaching experience with the two teams and a total of 12 years of collegiate soccer coaching experience. Approximately $95 \%$ of the sessions the MPCs conducted with the soccer student-athletes were conducted in an indoor classroom, with only the occasional session conducted in the bleachers on the soccer field following a practice. However, discussions between the MPCs and coaching staff revolved around the possibility of assessing the effectiveness of these group sessions in a more authentic "real-world" environment, namely outdoors on the soccer field. The skills the MPCs selected to address were based on discussions with the coaching staff, student-athletes, and also through the MPCs own observations of the teams. Specifically, pre- and post-test activities were designed and selected for the men's and women's teams to address each team's respective weaknesses from the previous season, based off of observations and discussions with those involved. The head coach was the same for both the men's and women's teams, and he desired to create distinction so that the two teams were not seen as one large team. Thus, it was determined that creating assessments for each team individually would help the teams to establish individuality.

\section{Program and Assessment Delivery}

Throughout the off-season, collegiate male $(n=25)$ and female $(n=20)$ soccer studentathletes received imagery, self-talk, and perceptual-cognitive training on a bi-weekly basis from four MPCs. Each topic was addressed separately, with three to five sessions devoted to each topic. Prior to receiving mental skills training, these student-athletes were assigned to small groups of five (women) or six (men), balanced by years on the team and playing position, and completed a pre-test at the beginning of one off-season and a post-test at the end of the offseason (three months). The off-season was selected as the ideal time for this program, given 
87 there was more time available to work on the mental skills and the off-season has been

107 testing.
At the beginning of both pre-test days, student-athletes were told that the purpose of the field day was to test them in groups on different activities relating to the goals set by the coaching staff, the players, and the MPCs. The student-athletes were instructed that they would be divided into groups and would work to earn a group score, thus adding a social and competitive nature to the activities. The student-athletes were only instructed they would be competing against each other, they were not told there would be any reward, however, the MPCs had previously observed the student-athletes put more effort into practices and activities when they were told they would be competing against each other. The student-athletes were also informed that a second day with the same activities (the post-test) would be set at the end of their spring off-season. The groups would be assessed on their improvement on the activities.

During both the pre- and post-testing, the groups rotated between three different stations created and led by the MPCs. During the time period when one group was not participating in one of the assessments, they were instructed to sit in bleachers off to the side of the field and not engage with the other groups. Student-athletes spent 12 minutes at each station before a whistle was blown and athletes rotated onto the next station. The entire assessment procedure took approximately one hour in total. During the post-test, student-athletes were placed into the same groups as they had been during the pre-test and participated in the same stations as they had done in the pre-test. Findings were not discussed with the athletes or coaching staff until after the post- 
A total of four assessments were developed by the MPCs, based off the literature, observations of the specific teams at hand, discussions with the student-athletes and coaching staff, and extensive feedback from a supervisor with over 30 years of applied consulting experience with collegiate and elite athletes. Both the men's and women's teams participated in the shooting self-efficacy and performance under pressure and fatigue conditions tasks, while the men also participated in an assessment of situational and tactical awareness, and the women participated in an on-field communication assessment. These assessments were selected to address each team's respective weaknesses from the previous season, based off of observations and discussions with those involved; hence there were different tasks for each gender.

\section{Situational and Tactical Awareness (Men Only)}

Tactical awareness pertains to the ability to adapt to moment-to-moment information during high pressure-situations (Gréhaigne, Godbout, \& Bouthier, 1999). It is essential for teammates to also be aware of their team members' individual traits, the team strategy, characteristics of the task at hand, and contextual constraints at large (personal-task-teamcontextual awareness; see Filho, Bertollo, Robazza, \& Comani, 2015). In other words, to successfully adapt to ever-changing performance constraints and achieve team synchronization, team members must develop extant personal-task-team and situational shared schemas. Under pressure, teams frequently transition to a more implicit type of coordination relying on Shared Mental Models, or a team's shared representation of knowledge (SMM; Entin \& Serfaty, 1999). Gershgoren et al. (2016) organized SMM into hierarchical levels with situational cognitions being the most specific one. This level was composed of both game intelligence and game plan components, with game intelligence revolving around anticipation skills given present information. The concept of the game plan centers on the athlete's ability to 
132

understand and execute tactical instructions (i.e., tactical understating). To operate synchronically as a team, tactical understanding and execution relies on the players' agreement on their positioning on the field (Gershgoren et al., 2016).

To assess both tactical and situational awareness, a small-sided field was set up, and two groups played a 10 minute scrimmage against each other, with the element of competition adding pressure. Athletes were provided the following initial instructions for both assessments, "your two teams will be playing a 10 minute small-sided scrimmage against each other. Periodically, when we blow the whistle you should stop and freeze where you are." During the scrimmage, the MPC periodically blew a whistle to stop play, and the student-athletes were asked to close their eyes and point to where two other student-athletes on their own team were positioned (closest and farthest) and then two student-athletes from the opposing team (i.e., situational awareness). Situational awareness was scored by measuring the distance from the individual's actual physical placement and the student-athlete's estimated positioning in 15 degree increments. To assess tactical awareness, when the MPC blew the whistle the student-athletes were asked to rate the correctness of their teammates' field position on a scale of 1 (poor) to 10 (very good) based on where the ball was. Tactical awareness was scored by computing an average score for each student-athlete, for each small group, and for the entire team collectively. See Figure 1 for a sample diagram of this assessment. Two MPCs independently completed ratings for both tasks, and interrater reliability revealed a high degree of consistency between the MPCs ratings ( $\mathrm{K}=$ $.88, \mathrm{p}<.001$ and $\mathrm{K}=.91, \mathrm{p}<.001$, respectively).

\section{On-Field Communication (Women Only)}

Employing a communication skills training program for interactive teams has been shown to be positively evaluated by the athletes (Sullivan, 1993). Additionally, previous research 
155

has found a positive relationship between team communication and team success (e.g., Lausic, Tenenbaum, Eccles, Jeong, \& Johnson, 2009; Sullivan, 1993). In one study, Sullivan (1993) found that athletes positively evaluated a communication skills training program for interactive teams. Specifically, athletes reported the program raised awareness of their strengths and weaknesses in communication skills and provided them with opportunities to practice skills and improve upon their weaknesses. Lausic et al. (2009) examined doubles tennis teams and found successful teams communicated more often than less successful teams, and had a more homogeneous model of communication. Therefore, a task was designed to assess the ratio of positive, negative, and neutral on-field comments for the women's soccer team specifically.

For the communication task a small-sided field was set up and the two groups played a 10 minute scrimmage against each other. Student-athletes were not informed that the station was measuring communication, rather, they were merely given the instructions, "your two teams will be playing a 10 minute small-sided scrimmage against each other." Four MPCs recorded the number of positive, negative, and neutral comments heard within each team. Comments directed toward the opposing team were not included. An example of a positive comment was "Great pass!”, whereas “That was an awful shot!” was recorded as a negative comment. Neutral comments were comments such as, "I've got ball." Two MPCs were assigned to record data for each team to ensure reliability $(\mathrm{K}=.96, \mathrm{p}<.001)$, and the number of positive, negative, and neutral comments made were averaged between the two researchers. This assessment was scored by calculating the ratio of positive to negative comments.

\section{Shooting Self-Efficacy (Men and Women)}

Imagery, creating or recreating experiences in the mind utilizing multiple senses and involving moods and emotions, is often considered the most popular mental training technique 
178

179 180

that athletes use (Weinberg, 2008; Weinberg \& Gould, 2015). Athletes use imagery for a number of different reasons, including skill practice and enhancing self-confidence (Weinberg, 2008;

Weinberg \& Gould, 2015). In addition to the relationship between imagery use and performance, several studies have shown a positive relationship between imagery use and confidence or selfefficacy, which can be defined as one's belief in one's ability to produce desired effects by one's actions (Bandura, 1997). Several studies found that using an imagery intervention enhanced athletes' confidence in their playing ability in various different sport athletes (see Weinberg, 2008).

Therefore, the self-efficacy task was designed to measure the athletes' self-efficacy for shooting and test if their self-efficacy and skill could be improved by using imagery. The athletes were given five balls each to shoot from the penalty mark into a regulation sized flat goal that was divided up into six areas by duct tape. They were shown Figure 2 noting the points available for each area, with more difficult shots resulting in a greater number of points available. Athletes were given the following instructions, "Your task is to score as many points as possible. You'll each take five shots from the penalty mark, and prior to each shot you'll tell us which area you're aiming for based on a diagram of the goal area. Your task is to score as many points as possible." The athletes were required to indicate which area they were aiming for prior to each shot. The MPC recorded which area the athlete was aiming for and which area the ball was shot into using Figure 3. Thus, accuracy of shots was used to measure shooting skill, and choice of target area was used to measure self-efficacy (difficult target area = high self-efficacy).

\section{Performance under Pressure and Fatigue Conditions (Both Men and Women)}

The relationship between pressure and performance deterioration has been well studied (for a review see Beilock \& Gray, 2007). Athletes encounter a wide array of physical and 
201

202

203

204

205

206

207

208

209

210

211

212

213

214

215

216

psychological demands that can impact performance, stemming from a variety of sources, including physical fatigue and both internal and external pressures and performance expectations (Weinberg \& Gould, 2015). The ability to perform at one's peak despite these various physical and psychological demands can be developed by a number of different strategies, including through mental skills training. Additionally, coaches and practitioners can integrate increasingly more demanding mental and physical challenges into training to also enhance athletes' ability to perform well under pressure (Bell, Hardy, \& Beattie, 2013).

This assessment challenged the athletes to push physically and mentally through fatigue competing against one another using a speed and accuracy trade-off task, thus creating a performance under time pressure task. Student-athletes were instructed to make as many shots as possible in 35 seconds. Student-athletes began the task by completing a 10 yard sprint to a cone and then sprinted another 10 yards back to their starting cone where they then took a shot on a four foot goal that was 10 yards away from their shooting position (see Figure 4). The studentathlete continued this process of sprinting then shooting until the 35 seconds expired. The total numbers of goals scored was calculated as a measurement of performance.

\section{Results}

The field assessment experience provided a good method for the MPCs to observe improvements in mental skills. Weinberg and Gould (2015) recommended observations be used as one method of assessing sport psychology intervention effectiveness. On the women's team, we observed an increase in the ratio of positive to negative comments from 1.65:1 (pre-test) to 2.50:1 (post-test), an increase in shot accuracy on the performance under fatigue task from $56.7 \%$ to $75.7 \%$, an increase in self-reported shooting self-efficacy from 20.6 (out of a total of 25 points) to 24, as well as an increase in actual points (obtained from the number of shots correctly 
224 made compared to what the student-athlete predicted) from 10.4 to 12.33 . On the men's side,

225 there was an increase in shot accuracy on the performance under fatigue task from $66.7 \%$ to

$22680 \%$, an improvement in situational awareness from an error of 17.10 degrees to 15 , but a small

227 decrease in tactical awareness from an average rating of 6.95 to 6.02 . On the situational

228 awareness task the student-athletes were most inaccurate when trying to gauge where the farthest

229 opponent was located. On the tactical awareness task, we estimate the possible decrease was due

230 to the lack of practice and games the team had during spring off season. Additionally we

231 observed no improvement on self-efficacy or shooting accuracy; however, we had designed this

232 activity specifically with the women's team in mind.

233 Upon completion of the field assessment and its analysis, a performance report was

234 provided to the student-athletes and the coaches and professional recommendations for

235 performance enhancement were discussed. The coaching staff was provided with a detailed

236 report for each individual student-athlete as well as for each team. The student-athletes were

237 provided with their own individual results as well as their overall team results during a team

238 meeting. The MPCs led discussions with both teams regarding their areas of improvement from

239 pre- to post-test, and also provided recommendations for both teams to work on moving forward.

240 Student-athletes were also given the opportunity to meet individually with the MPCs to further

241 discuss their results and develop an individual plan. Both student-athletes and coaches reported

242 that the activities and debrief demonstrated the involvement of mental skills in every aspect of

243 their soccer performance. During the post-testing, numerous athletes asked to stay longer to

244 repeat a station as they felt the stations were very tangible representations of their mental skills

245 and were motivated to continue improving their mental skills. Additionally, the student-athletes

246 asked to move more of the group sessions outdoors to the soccer field as they enjoyed being able 
247

248

249

250

to see first-hand how the mental skills could be applied to various soccer skills and tasks.

Furthermore, they claimed to acquire a better understanding of how psychological skills may be utilized in soccer. Such an understanding may motivate athletes and coaches to commit more time to developing psychological skills.

\section{Recommendations for Practitioners}

Despite the overwhelmingly positive feedback, there are limitations to assessing mental skills in a field-based setting that practitioners should consider. While these student-athletes improved from pre- to post-test, many of these improvements (e.g., positive to negative comment ratios) were not substantial, therefore practitioners should consider this when deciding to take the time to implement field-based assessments such as these. Moving assessments and activities to a more authentic setting, such as a soccer field, does provide a less controlled environment to work in. For example, a public or open location could result in varied weather conditions. Additionally, these assessments were more timely to develop, set-up, and administer than questionnaires or other evaluations. Furthermore, due to the time, location, and resources required for these assessments, they would not have been possible without full support from the coaching staff. It is important to note that an open and strong relationship with the coaching staff is essential and their input in discussing issues, developing interventions, and designing assessments is the key to a productive and effective mental skill training program (Weinberg \& Gould, 2015; Zakrajsek et al., 2011).

Given the qualitative feedback provided by both the student-athletes and coaches, we believe this on-field assessment served its purpose in aiding with "buy-in" from both studentathletes and coaches by providing them with a more tangible demonstration of the usefulness and impact of mental skills on performance. Indeed, these attitudes support previous research 
270 indicating that one of the main reasons coaches and athletes don't use sport psychology services

271 is because of their failure to understand the link to performance (Zakrajsek et al., 2011). Thus,

272 more sport psychology consultation sessions should be conducted in the field and outdoors, so

273 that athletes and coaches associate mental skills with performance improvements (Gee, 2010). It

274 is strongly recommended that sport psychology practitioners working with a variety of sports

275 consider using assessments such as this one alongside questionnaires or other measures of sport

276 psychology effectiveness.

277

278 
279

280

281

282

283

284

285

286

287

288

289

290

291

292

293

294

295

296

297

298

299

300

301
References

Bandura, A. (1997). Self-efficacy: The exercise of control. New York: W. H. Freeman \& Company.

Beckmann, J., \& Kellman, M. (2003). Procedures and principles of sport psychological assessment. The Sport Psychologist, 17, 338-350.

Beilock, S. L., \& Gray, R. (2007). Why do athletes choke under pressure? In G. Tenenbaum \& R. C. Eklund (Eds.), Handbook of sport psychology (pp. 425-444). Hoboken, NJ, US: John Wiley \& Sons Inc.

Bell, J. L., Hardy, L, \& Beattie, S. (2013). Enhancing mental toughness and performance under pressure in elite young cricketers: A 2-year longitudinal intervention. Sport, Exercise, and Performance Psychology 2(4), 281-297.

Blann, F. W., Shelley, G., \& Gates, S. C. (2011). Marketing sport psychology consulting services. Journal of Sport Psychology in Action, 2(1), 33-52.

Entin, E. E., \& Serfaty, D. (1999). Adaptive team coordination. Human Factors, 41, 312-325.

Filho, E., Bertollo, M., Robazza, C., \& Comani, S. (2015). The juggling paradigm: a novel social neuroscience approach to identify neuropsychophysiological markers of team mental models. Frontiers in Psychology, 1-6.

Gee, C. J. (2010). How does sport psychology actually improve athletic performance? A framework to facilitate athletes' and coaches' understanding. Behavior Modification, 34, 386-402.

Gershgoren, L., Basevitch, I., Gershgoren, A., Brill, Y. S., Schinke, R. J., \& Tenenbaum, G. (2016). Expertise in soccer teams: A thematic inquiry into the role of shared mental models within team chemistry. Psychology of Sport and Exercise, 24, 128-139. 
302

Gréhaigne, J., Godbout, P., \& Bouthier, D. (1999). The foundations of tactics and strategy in team sports. Journal of Teaching in Physical Education, 18, 159-174.

Lausic, D., Tenenbaum, G., Eccles, D., Jeong, A., \& Johnson, T. (2009). Intrateam communication and performance in doubles tennis. Research Quarterly for Exercise and Sport, 80(2), 281-290.

Sullivan, P. A. (1993). Communication skills training for interactive sports. Sport Psychologist, 7, 79-91.

Weinberg, R. S. (2008). Does imagery work? Effects on performance and mental skills. Journal of Imagery Research in Sport and Physical Activity, 3(1), 1-21.

Weinberg, R. S., \& Gould, D. (2015). Foundations of sport and exercise psychology (6 ${ }^{\text {th }}$ ed). Champaign, IL: Human Kinetics.

Woodcock, C., Duda, J. L., Cumming, J., Sharp, L. A., \& Holland, M. J. (2012). Assessing mental skill and technique use in applied interventions: Recognizing and minimizing threats to the psychometric properties of the TOPS. The Sport Psychologist, 26(1), 1-15.

Zakrajsek, R. A., Martin, S. B., \& Zizzi, S. J. (2011). American high school football coaches' attitudes toward sport psychology consultation and intentions to use sport psychology services. International Journal of Sports Science \& Coaching, 6, 461-478. 